\title{
$\begin{array}{ll}\text { Research Square } & \text { Preprints are preliminary reports that have not undergone peer review. } \\ \text { They should not be considered conclusive, used to inform clinical practice, } \\ \text { or referenced by the media as validated information. }\end{array}$
}

\section{The related factors of pre-diabetes among adolescents in Qingdao, China}

\author{
Yue Wu \\ the Affiliated Hospital of Qingdao University \\ Lili WEi ( $\boldsymbol{D} 1441500228 @ q q . c o m$ ) \\ Affiliated Hospital of Qngdao University
}

Research article

Keywords: prediabetes, adolescents, risk factors

Posted Date: September 30th, 2019

DOI: https://doi.org/10.21203/rs.2.15581/v1

License: (9) This work is licensed under a Creative Commons Attribution 4.0 International License. Read Full License 


\section{Abstract}

Background: To analyze the related factors of pre-diabetes among adolescents.

Methods: 588 students were selected by convenient sampling method from Qingdao for questionnaires, physical examination and biochemical examination. Multivariate analysis was carried out to analyze the related factors among adolescents.

Results: Overweight/obesity, central obesity, family history of diabetes, weekly frequency of moderate to vigorous physical exercise $<7$ days, weekly frequency of sugar-sweetened beverage consumption $<7$ days were statistically difference in the prevalence of prediabetes among boys. Family history of diabetes, weekly screen time $\geq 14 \mathrm{~h}$, weekly frequency of fast food consumption $\geq 7$ days were significantly difference in the prevalence of diabetes among girls.

Conclusions: Our study find that prediabetes among adolescents in Qingdao is becoming a vital health issue. This requires us to avoid obesity and develop a healthy lifestyle

\section{Background}

Pre-diabetes, also known as impaired glucose regulation (IGR), is characterized by insulin secretion dysfunction and insulin resistance[1], including three states: impaired fasting glucose (IFG), impaired glucose tolerance (IGT), IFG and IGT. The diagnostic criteria of the World Health Organization (WHO) [2] are: IFG means that fasting plasma glucose (FPG) 6.1-7.0mmol/L, and 2 hours blood glucose (2hPG) after $75 \mathrm{~g}$ oral glucose tolerance test (OGTT) $<7.8 \mathrm{mmol} / \mathrm{L}$. IGT refers to FPG $<7.0 \mathrm{mmol} / \mathrm{L}$, and $2 \mathrm{hPG}$ after $75 \mathrm{~g}$ OGTT 7.8-11.1mmol/L. The diagnostic criteria of the American Diabetes Association (ADA)[3] are: IFG 5.6-6.9mmol/L, 2hPG 7.811.0mmol/L, and hemoglobin A1c (HbA1C) 5.7\%-6.4\%. In recent years, the proportion of adolescents with prediabetes among adolescents has been increasing. According to statistics, the proportion of pre-diabetes among adolescents in the United States from 1999 to 2014 was 15.5\%[4]. The proportion of pre-diabetes among nondiabetic adolescents in the United States from 1994 to 2008 accounted for 36.6\%[5].

With the increasing prevalence of adolescent obesity, the prevalence of adolescent diabetes is increasing globally [6-8]. In Thailand, the incidence of adolescent diabetes increased from 10\%-15\% in 1995 to 35\% -40\% in 2014 [9]. During the United States from 2001 to 2009, the prevalence of adolescents with type 1 diabetes increased by $21.1 \%$ and the prevalence of type 2 diabetes increased by 30.5\% [10]. Pre-diabetes is an abnormal state of glucose metabolism between normal glucose metabolism and diabetes. It is an inevitable stage of diabetes and the most important risk factor for diabetes. It is reported that about $5 \%-10 \%$ in the pre-diabetes population of people will progress to diabetes within 1 year [11], a prospective study showed that the prediabetes population had a higher proportion of diabetes (74\%) than those with normal glucose metabolism (48.7\%)[12]. Diabetes is one of the three major diseases that threaten the health of adolescents. It is an 
irreversible lifelong disease and requires lifelong treatment once develops, which not only causes serious complications such as macrovascular and microvascular diseases, but also bring huge economic burden to individuals and countries. Pre-diabetes is a reversible stage and is the only stage we have learned that may turn blood sugar back to normal. If we can understand the influencing factors affecting the pre-diabetes, then doing effective health education and intervention for this stage of the population, it will prevent the progression of prediabetes to irreversible diabetes, then reduce the harm caused by diabetes, improve the quality of life of patients and reduce the economic burden of patients and countries.

Although pre-diabetes is asymptomatic, it is not a harmless state. It causes a reduction in the volume of gray matter, which affects the brain, leading to cognitive impairment[13]. In the implantation of teeth, it increases the risk of inflammation of the soft tissue and alveolar bone damage due to its hyperglycemia [14]. Pre-diabetes is associated with the development of cardiovascular disease, which increases the risk of cardiovascular disease such as stroke and coronary heart disease [15], and increases the risk of macrovascular and microvascular disease [16]. Pre-diabetes will increase the risk of liver fibrosis [17]. In addition, pre-diabetes is also associated with poor prognosis of a variety of diseases, such as increasing adverse prognosis of ischemic stroke[18] and mortality of infective endocarditis[19]. Thus, the purpose of this study was to analyze relatedk factors associated with pre-diabetes in adolescents in Qingdao, China.

\section{Methods}

\section{Subjects}

During 2018, we obtained information on 588 students aged from 12 to 18 years attending 3 junior high schools and 2 senior high schools in Qingdao, China. Students with confirmed diabetes were excluded. All participants and parents signed informed consent. This study was approved by the Ethics Committee of the Affiliated Hospital of Qingdao University.

\section{Research methods}

\section{Questionnaire date}

We used questionnaire to collect demographic information, including age, sex, family history of diabetes, weekly frequency of fast food consumption( $\geq 7$ day per week and $<7$ day per week), weekly frequency of sugarsweetened beverage consumption( $\geq 7$ day per week and $<7$ day per week), weekly screen time ( $\geq 14$ hours per week and $<14$ hours per week), and weekly frequency of moderate to vigorous physical exercise ( $\geq 7$ days per week and $<7$ days per week). All data were collected by well-trained research staff members.

\section{Anthropometry}

Anthropometric variables, including height, weight, waist circumference (WC), blood pressure (BP) were measured by research staff members obtaining the nurse qualification certificate. Height and weight were measured to the nearest $0.1 \mathrm{~cm}$ and $0.1 \mathrm{~kg}$, respectively. WC were measured to the nearest $0.1 \mathrm{~cm}$. Average BP 
was computed by averaging 2 measurements of systolic blood pressure (SBP) and diastolic blood pressure (DBP). Body mass index (BMI) was calculated by weight (kg) divided by the square of height (m).

\section{Laboratory data}

Each student collected $\mathrm{a} \geq 8 \mathrm{~h}$ fasting blood specimen. FPG level were measured by hexokinase.

\section{Definitions}

A fasting blood sugar of $\geq 5.5 \mathrm{mmol} / \mathrm{L}$ was the criteria for diagnosing pre-diabetes[20]. Family history of diabetes was defined as having any first- or second-degree family member with diabetes. The screen time was referred to the time of watching TV, using computer and using smartphone. The moderate to vigorous physical exercise was referred to that which can lead to an increase in sweat, breathing, and heartbeat. A BMI above the 85th percentile for this particular age group was considered overweight/obesity[21]. A WC above the 90th percentile for this particular age group was considered central obesity [22]. A DBP and/or SBP above the 95th percentile for this particular age group was considered hypertension [23]. A waist-to-height ratio $\geq 0.5$ was used to identify students with excess central fat distribution.

\section{Statistics Analysis}

The data were statistically analyzed by SPSS 23.0 software. The qualitative data were described by frequency and composition ratio. The quantitative data were described by mean \pm standard deviation (' $x \pm s$ ). Logistic regression model was used to conduct multivariate analysis of variables. $P<0.05$ was considered statistically significant.

\section{Results}

Profile of study participants by gender

A total of 588students in this research (278 boys and 310 girls). The students were between 12 and $18 y e a r s$ of age $($ mean $=15.02 \pm 1.81)$. The prevalence of normal blood glucose was $81.1 \%$, and that of pre-diabetes was 18.9\%. Table 1 contains summary data for boys and girls. There were no significant differences in overweight/obesity, central obesity, waist-to-height ratio, hypertension, family history of diabetes, weekly screen time, weekly frequency of fast food consumption. The girls had significantly higher weekly frequency of moderate to vigorous physical exercise $\left(\chi^{2}=27.045, P<0.001\right)$, elevated blood sugar $\left(\chi^{2}=4.931, P=0.026\right)$ compared with boys. The boys had significantly higher weekly frequency of sugar-sweetened beverage consumption $\left(\chi^{2}=27.713, P<0.001\right)$ compared with girls.

Table 1 Profile of study participants by gender 


\begin{tabular}{|c|c|c|c|c|}
\hline Virables & Boys $\square n=278 \square$ & Girls $\square n=310 \square$ & $\chi^{2}$ & $P$ value \\
\hline Overweight/obesity & & & 0.033 & 0.856 \\
\hline no & 218 & 245 & & \\
\hline yes & 60 & 65 & & \\
\hline Central obesity & & & 0.036 & 0.849 \\
\hline no & 237 & 266 & & \\
\hline yes & 41 & 44 & & \\
\hline waist-to-height ratio & & & 0.283 & 0.595 \\
\hline$<0.5$ & 241 & 264 & & \\
\hline$\geq 0.5$ & 37 & 46 & & \\
\hline Hypertension & & & 3.234 & 0.072 \\
\hline no & 208 & 251 & & \\
\hline yes & 70 & 59 & & \\
\hline family history of diabetes & & & 2.957 & 0.086 \\
\hline no & 235 & 245 & & \\
\hline yes & 43 & 65 & & \\
\hline weekly screen time & & & 1.999 & 0.157 \\
\hline$\geq 14 \mathrm{~h}$ per week & 53 & 74 & & \\
\hline$<14$ h per week & 225 & 236 & & \\
\hline \multicolumn{3}{|c|}{ weekly frequency of moderate to vigorous physical exercise } & 27.045 & $<0.001$ \\
\hline$\geq 7$ days per week & 76 & 33 & & \\
\hline$<7$ day per week & 202 & 277 & & \\
\hline \multicolumn{3}{|c|}{ weekly frequency of sugar-sweetened beverage consumption } & 27.713 & $<0.001$ \\
\hline$\geq 7$ day per week & 189 & 267 & & \\
\hline$<7$ day per week & 89 & 43 & & \\
\hline \multicolumn{3}{|c|}{ weekly frequency of fast food consumption } & 0.442 & 0.506 \\
\hline$\geq 7$ days per week & 126 & 149 & & \\
\hline$<7$ day per week & 152 & 161 & & \\
\hline Elevated blood sugar & & & 4.931 & 0.026 \\
\hline no & 215 & 262 & & \\
\hline yes & 63 & 48 & & \\
\hline
\end{tabular}

Table 2 shows the gender-wise breakdown of prediabetes in relation to the presence or absence of various risk factors. Multivariate analysis was carried out separately in girls and boys. Overweight/obesity $(O R=2.734$, $95 \% C I=1.351-5.534)$, central obesity $(O R=4.180,95 \% C I=1.865-9.369)$, family history of diabetes (OR=3.105, $95 \% C I=1.392-6.924)$, weekly frequency of moderate to vigorous physical exercise $<7$ days $(O R=4.250$, $95 \% C I=1.751-10.315)$, weekly frequency of sugar-sweetened beverage consumption < 7 days $(O R=2.276$, $95 \% C I=1.149-4.505)$ were statistically difference in the prevalence of prediabetes among boys. Family history of diabetes $(O R=3.511,95 \% C I=1.768-6.973)$, weekly screen time $\geq 14 \mathrm{~h}(O R=2.102,95 \% C I=1.035-4.268)$, weekly frequency of fast food consumption $\geq 7$ days $(O R=2.058,95 \% C I=1.050-4.036)$ were significantly difference in the prevalence of diabetes among girls.

Table 2 prevalence of risk factors contributing to prediabetes in boys and girls 


\begin{tabular}{|c|c|c|}
\hline Virables & $O R$ & $95 \% C I$ \\
\hline \multicolumn{3}{|c|}{ prevalence of prediabetes in boys } \\
\hline \multicolumn{3}{|l|}{ Overweight/obesity } \\
\hline no & 1.000 & \\
\hline yes & 2.734 & $1.351-5.534^{\mathrm{a}}$ \\
\hline \multicolumn{3}{|l|}{ Central obesity } \\
\hline no & 1.000 & \\
\hline yes & 4.180 & $1.865-9.369^{\mathrm{a}}$ \\
\hline \multicolumn{3}{|l|}{ waist-to-height ratio } \\
\hline$<0.5$ & 1.000 & \\
\hline$\geq 0.5$ & 1.535 & $0.548-4.297$ \\
\hline \multicolumn{3}{|l|}{ Hypertension } \\
\hline no & 0.531 & $0.257-1.094$ \\
\hline yes & 1.000 & \\
\hline \multicolumn{3}{|c|}{ family history of diabetes } \\
\hline no & 1.000 & \\
\hline yes & 3.105 & $1.392-6.924^{\mathrm{a}}$ \\
\hline \multicolumn{3}{|l|}{ weekly screen time } \\
\hline$<14$ h per week & 0.501 & $0.239-1.049$ \\
\hline$\geq 14 \mathrm{~h}$ per week & 1.000 & \\
\hline \multicolumn{3}{|c|}{ weekly frequency of moderate to vigorous physical exercise } \\
\hline$<7$ days per week & 4.250 & $1.751-10.315^{\mathrm{a}}$ \\
\hline$\geq 7$ days per week & 1.000 & \\
\hline \multicolumn{3}{|c|}{ weekly frequency of sugar-sweetened beverage consumption } \\
\hline$<7$ days per week & 2.276 & $1.149-4.505^{\mathrm{a}}$ \\
\hline$\geq 7$ days per week & 1.000 & \\
\hline \multicolumn{3}{|c|}{ weekly frequency of fast food consumption } \\
\hline$<7$ days per week & 0.976 & $0.505-1.884$ \\
\hline$\geq 7$ days per week & 1.000 & \\
\hline \multicolumn{3}{|c|}{ prevalence of prediabetes in girls } \\
\hline \multicolumn{3}{|c|}{ Overweight/obesity } \\
\hline no & 1.000 & \\
\hline yes & 1.662 & $0.777-3.555$ \\
\hline \multicolumn{3}{|l|}{ Central obesity } \\
\hline no & 1.000 & \\
\hline yes & 1.205 & $0.439-3.308$ \\
\hline \multicolumn{3}{|l|}{ waist-to-height ratio } \\
\hline$<0.5$ & 1.141 & $0.434-2.997$ \\
\hline$\geq 0.5$ & 1.000 & \\
\hline \multicolumn{3}{|l|}{ Hypertension } \\
\hline no & 1.000 & \\
\hline & 1.078 & $0.434-2.676$ \\
\hline \multicolumn{3}{|c|}{$\begin{array}{l}\text { yes } \\
\text { family history of diabetes }\end{array}$} \\
\hline no & 1.000 & \\
\hline yes & 3.511 & $1.768-6.973^{\mathrm{a}}$ \\
\hline \multicolumn{3}{|l|}{ weekly screen time } \\
\hline$<14$ h per week & 1.000 & \\
\hline$\geq 14 \mathrm{~h}$ per week & 2.102 & $1.035-4.268^{\mathrm{a}}$ \\
\hline \multicolumn{3}{|c|}{ weekly frequency of moderate to vigorous physical exercise } \\
\hline$<7$ days per week & 1.533 & $0.412-5.703$ \\
\hline$\geq 7$ days per week & 1.000 & \\
\hline
\end{tabular}




\begin{tabular}{lcc}
\hline \multicolumn{3}{l}{ weekly frequency of sugar-sweetened beverage consumption } \\
\hline$<7$ days per week & 1.000 & \\
\hline$\geq 7$ days per week & 0.940 & $0.348-2.539$ \\
\hline weekly frequency of fast food consumption & \\
\hline$>7$ days per week & 1.000 & \\
$\geq 7$ days per week & 2.058 & $1.050-4.036^{\mathrm{a}}$ \\
\hline
\end{tabular}

\section{Discussion}

In this study, those who with pre-diabetes accounted for $18.9 \%$ of non-diabetic adolescents. Previous studies[5] showed that those who with pre-diabetes accounted for $36.6 \%$ of non-diabetic adolescents in the United States from 1994 to 2008. Different prevalence of prediabetes may because of the sampling method, participant age, ethnicity region, or sampling size. Furthermore, the results may have been overestimated because only one blood sample was collected to measure fasting blood glucose levels in this study.

The study found that the prevalence of prediabetes among boys were higher than girls which was similar to the results of previous studies[20, 24]. This phenomenon may be caused by hormones[25]. An animal experiment showed that ovary and estrogen can increase brown tissue in the body[26], while the activity of brown tissue can reduce insulin resistance[27]. Moreover there are also some research studies show that there is no significant gender difference in the prevalence of prediabetes among adolescents[28]. This indicates that the prevalence of prediabetes in gender is needed a lot of research in the later stage to explore.

Multivariate analysis showed that overweight/obesity, central obesity, family history of diabetes, weekly frequency of moderate to vigorous physical exercise $<7$ days per week, weekly frequency of sugar-sweetened beverage consumption $<7$ days per week were high-risk groups in pre-diabetes among boys. Family history of diabetes, weekly screen time $\geq 14 \mathrm{~h}$ per week, weekly frequency of fast food consumption $\geq 7$ days per week were high-risk groups in pre-diabetes among girls. Previous studies[29] showed that those who with abnormal homeostasis model assessment of insulin resistance(HOMA-IR) have a higher prevalence of prediabetes among boys and those who with 12-19years old, acanthosis nigricans, family history, overweight, abdominal obesity, and abnormal HOMA-IR have a higher prevalence of prediabetes among girls. Ravinder Mamtani[30] concluded that gender, family of diabetes and waist-to-height ratio $>0.5$ were risk factors with prediabetes among adolescents. Chen CM[28] thought that male, age, family dietary environment, overweight/obesity, cardio-metabolic(high TG, low HDL-C, high BP) were related factors of prediabetes among adolescents.

Previous studies[31-35] showed that insulin resistance index increasing significantly with overweight/obese, waist circumference increasing, and physical exercise decreasing. Diabetes has a high degree of genetic heterogeneity, while family history is an important indicator of genetic factors. Diabetic family has a similar genetic background, so there will be obvious family aggregation. Pre-diabetes is a necessary stage of diabetes, 
so it may have a common pathogenesis with diabetes. In addition, Mohammad Almari et al[34] found that the impact of family history of diabetes on pre-diabetes in adolescents was related to gender, for example, mothers with diabetes may increase the risk of pre-diabetes in their sons and fathers with diabetes may increase the risk of pre-diabetes in his daughter. Claire M Nightingale et al [36] found that the level of insulin resistance with those average daily screen time $>3 \mathrm{~h}$ was higher than those with average daily screen time $<1 \mathrm{~h}$. The study of Henderson et al[37] showed that insulin sensitivity decreasing by $5 \%$ for every $1 \mathrm{~h}$ increasing in screen time. Jiantao Ma[38] showed that excessive intake of sugar-sweetened beverages was associated with increasing risk of pre-diabetes $(P<0.001)$ and increasing insulin resistance index $(P=0.006)$. When the body ingests too much sugar-sweetened beverages, it will increases the fat synthesis in the liver. During the progress, the sugars can be converted into substances that impair insulin sensitivity such as diacylglycerol. Sairaman Nagarajan[39] shows that healthy food availability was associated with a decreased adjusted prevalence of prediabetes in adolescents.

This study has several limitations. First, the study is a cross-section study, so it can not explain the causal relationship between pre-diabetes and these factors. Second, the sample selected from Qingdao has regional limitations and the sample size is limited. In the later stage, it is still necessary to expand the sample size and conduct multi-center cooperation research to explore the relationship between adolescents and pre-diabetes.

\title{
Conclusions
}

In conclusion, our study find that prediabetes among adolescents in Qingdao is becoming a vital health issue. This requires us to avoid obesity and develop a healthy lifestyle.

\section{Declarations}

\author{
Abbreviations \\ IGR: impaired glucose regulation; IFG: impaired fasting glucose; IGT: impaired glucose tolerance; FPG: fasting \\ plasma glucose; 2hPG: 2 hours blood glucose; OGTT: oral glucose tolerance test; ADA: American Diabetes \\ Association; HbA1C: hemoglobin A1c; WC: waist circumference; BP: blood pressure; SBP: systolic blood \\ pressure; DBP: diastolic blood pressure; BMI: Body mass index; HOMA-IR: homeostasis model assessment of \\ insulin resistance
}

\section{Ethics approval and consent to participate}

The ethics were approved by the Ethics Committee of Affiliated Hospital of Qingdao University, and written informed consent was obtained from all of the participants and their parents before data collection.

\section{Consent for publication}

Not applicable

\section{Availability of data and materials}

The datasets used and analysed during the current study are available from the corresponding author on reasonable request. 
Competing interests

The authors declare no conflict of interest

Funding

No

Authors' contributions

LW had the original idea for the study, and, with all co-authors, carried out the design. YW and BW carried out the analyses and drafted the manuscript. HX and WJ provided valuable insight regarding the methodological approach and organization of the manuscript. All authors read and approved the final manuscript.

\section{Acknowledgements}

We express our gratitude to the participants and colleagues who were involved in the study. The authors have no competing interests

\section{References}

\section{References:}

1. Cai X, Xia L, Pan Y, He D, Zhu H, Wei T, He Y: Differential role of insulin resistance and $\beta$-cell function in the development of prediabetes and diabetes in middle-aged and elderly Chinese population. DIABETOL METAB SYNDR 2019, 11(24).

2. Alberti KG, Zimmet PZ: Definition, diagnosis and classification of diabetes mellitus and its complications. Part 1: diagnosis and classification of diabetes mellitus provisional report of a WHO consultation. Diabet Med 1998, 15(7):539-553.

3. American Diabetes, Association: Classification and Diagnosis of Diabetes:Standards of Medical Care in Diabetes-2018. DIABETES CARE 2018, 41(Supplement 1):S13-S27.

4. Lee AM, Fermin CR, Filipp SL, Gurka MJ, DeBoer MD: Examining trends in prediabetes and its relationship with the metabolic syndrome in US adolescents, 1999-2014. ACTA DIABETOL 2017, 54(4):373-381.

5. Zamora-Kapoor A, Fyfe-Johnson A, Omidpanah A, Buchwald D, Sinclair K: Risk factors for pre-diabetes and diabetes in adolescence and their variability by race and ethnicity. PREV MED 2018, 115:47-52.

6. Pulungan AB, Afifa IT, Annisa D: Type 2 diabetes mellitus in children and adolescent: an Indonesian perspective. Annals of Pediatric Endocrinology \& Metabolism 2018, 23(3):119-125.

7. Temneanu OR, Trandafir LM, Purcarea MR: Type 2 diabetes mellitus in children and adolescents: a relatively new clinical problem within pediatric practice. J Med Life 2016, 9(3):235-239.

8. Urakami T: Increased trend in the incidence of diabetes among youths in the USA during 2002-2012. J DIABETES INVEST 2017, 8(6):748-749.

9. Jaruratanasirikul S, Thammaratchuchai S, Sriplung H: Trends of childhood diabetes in Southern Thailand: 20-year experience in a tertiary medical center. WORLD J PEDIATR 2017, 13(6):566-570.

10. Dabelea D, Mayer-Davis EJ, Saydah S, Imperatore G, Linder B, Divers J, Bell R, Badaru A, Talton JW, Crume T et al: Prevalence of Type 1 and Type 2 Diabetes Among Children and Adolescents From 2001 to 2009. JAMA 2014, 311(17):1778-1786.

11. Tabák AG, Herder C, Rathmann W, Brunner EJ, Kivimäki M: Prediabetes: a high-risk state for diabetes development. The Lancet 2012, 379(9833):2279-2290.

12. Ligthart S, van Herpt TTW, Leening MJG, Kavousi M, Hofman A, Stricker BHC, van Hoek M, Sijbrands EJG, Franco OH, Dehghan A: Lifetime risk of developing impaired glucose metabolism and eventual progression from prediabetes to type 2 diabetes: a prospective cohort study. The Lancet Diabetes \& Endocrinology 2016, $4(1): 44-51$. 
13. Markus MRP, Ittermann T, Wittfeld K, Schipf S: Prediabetes is associated with lower brain gray matter volume in the general population. The Study of Health in Pomerania (SHIP). Nutrition, Metabolism \& Cardiovascular Diseases 2017, 27:1114-1122.

14. Alrabiah M, Alrahlah A, Al-Hamdan RS, Al-Aali KA, Labban N, Abduljabbar T: Survival of adjacentdental-implants in prediabetic and systemically healthy subjects at 5-years follow-up. CLIN IMPLANT DENT $R$ 2019, 21(2):232-237.

15. Huang Y, Cai X, Mai W, Li M, Hu Y: Association between prediabetes and risk of cardiovascular disease and all cause mortality: systematic review and meta-analysis. BMJ 2016, 355:i5953.

16. Herman WH: The global agenda for the prevention of type 2 diabetes. NUTR REV2017, 75(suppl 1):1318.

17. Koç AS, Sumbul HE: Prediabetes Is Associated With Increased Liver Stiffness Identified by Noninvasive Liver Fibrosis Assessment. ULTRASOUND Q 2019, 00(00):1-9.

18. JP M, M S, F L: Prediabetes Is Associated with Unfavorable Outcome in Young Adult Patients with Ischemic Stroke. J Stroke Cerebrovasc Dis 2018, 27(2):352-356.

19. Wei XB, Liu YH, Huang JL: Prediabetes and diabetes are both risk factors for adverse outcomes in infective endocarditis. Diabet Med 2018, 35(11):1499-1507.

20. Lee JM, Gebremariam A, Wu EL, LaRose J, Gurney JG: Evaluation of Nonfasting Tests to Screen for Childhood and Adolescent Dysglycemia. DIABETES CARE 2011, 34(12):2597-2602.

21. Group of China Obesity Task Force: Body mass reference norm for screening overweight and obesity in Chinese children and adolescents. Chin J Epidemiol, 2004(02):10-15.(Chinese)

22. MA Guan-sheng, JI Chengye, MA Jun, MI Jie, SONG Yinzi, XIONG Feng, YAN Weili, HU Xiaoqi, LI Yanping, DU Songming et al: Waist circumference reference values for screening ccardiovascular risk factors in Chinese children and adolescents aged 7-18 years. Chin J Epidemiol 2010, 31(6):609-615. (Chinese)

23. FAN Hui, YAN Yinkun, MI Jie,on behalf of the Chinese Child Blood Pressure Reference Collaborative Group: Updating blood pressure referencces for Chinese children aged 3-17 years. Chin J Hypertens 2017, 25(5):428-435. (Chinese)

24. Li C, Ford ES, Zhao G, Mokdad AH: Prevalence of Pre-Diabetes and Its Association With Clustering of Cardiometabolic Risk Factors and Hyperinsulinemia Among U.S. Adolescents: National Health and Nutrition Examination Survey 2005-2006. DIABETES CARE 2009, 32(2):342-347.

25. Kautzky-Willer A, Harreiter J, Pacini G: Sex and Gender Differences in Risk, Pathophysiology and Complications of Type 2 Diabetes Mellitus. ENDOCR REV2016, 37(3):278-316.

26. Grefhorst A, van den Beukel JC, van Houten ELA, Steenbergen J, Visser JA, Themmen AP: Estrogens increase expression of bone morphogenetic protein $8 \mathrm{~b}$ in brown adipose tissue of mice. BIOL SEX DIFFER 2015, $6(1)$.

27. Liu X, Wang S, You Y, Meng M, Zheng Z, Dong M, Lin J, Zhao Q, Zhang C, Yuan X et al: Brown Adipose Tissue Transplantation Reverses Obesity in Ob/Ob Mice. ENDOCRINOLOGY 2015, 156(7):2461-2469.

28. Chen CM, Lou MF, Gau BS: Prevalence of impaired fasting glucose and analysis of related factors in Taiwanese adolescents. PEDIATR DIABETES 2014, 15(3):220-228.

29. Ranjani H, Sonya J, Anjana RM, Mohan V: Prevalence of Glucose Intolerance Among Children and Adolescents in Urban South India (ORANGE-2). DIABETES TECHNOL THE 2013, 15(1):13-19.

30. Ravinder Mamtani ABLJ: Adolescent prediabetes in a high-risk Middle East country:

a cross-sectional study. Journal of the Royal Society of Medicine Open 2014, 5(8):1-5.

31. Sapunar J ANNJ: Alta prevalencia de trastornos nutricionales por exceso, resistencia insulínica y síndrome metabólico en escolares de la comuna de Carahue, Región de la Araucanía. Rev Med Chil 2018, 146(9):978-986. 
32. Park K, Lee D, Erickson DJ, Himes JH, Shikany JM, Jacobs DR: Association of Long-term Change in Waist Circumference With Insulin Resistance. OBESITY 2010, 18(2):370-376.

33. Berman LJ, Weigensberg MJ, Spruijt-Metz D: Physical activity is related to insulin sensitivity in children and adolescents, independent of adiposity: a review of the literature. Diabetes Metab Res Rev 2012, 28(5):395408.

34. Almari M, Alsaedi S, Mohammad A, Ziyab AH: Associations of adiposity and parental diabetes with prediabetes among adolescents in Kuwait: A cross-sectional study. PEDIATR DIABETES 2018, 19(8):1362-1369.

35. Stabelini NA, de Campos W, Dos SG, Mazzardo JO: Metabolic syndrome risk score and time expended in moderate to vigorous physical activity in adolescents. BMC PEDIATR 2014, 14(42):42.

36. Nightingale CM, Rudnicka AR, Donin AS, Sattar N, Cook DG, Whincup PH, Owen CG: Screen time is associated with adiposity and insulin resistance in children. ARCH DIS CHILD 2017, 102(7):612-616.

37. Henderson M, Benedetti A, Barnett TA, Mathieu M, Deladoëy J, Gray-Donald K: Influence of Adiposity, Physical Activity, Fitness, and Screen Time on Insulin Dynamics Over 2 Years in Children. JAMA PEDIATR 2016, 170(3):E1.

38. Ma J, Jacques PF, Meigs JB, Fox CS, Rogers GT, Smith CE, Hruby A, Saltzman E, McKeown NM: SugarSweetened Beverage but Not Diet Soda Consumption Is Positively Associated with Progression of Insulin Resistance and Prediabetes. The Journal of Nutrition 2016, 146(12):2544-2550.

39. Nagarajan S, Khokhar A, Holmes DS, Chandwani S: Family Consumer Behaviors, Adolescent Prediabetes and Diabetes in the National Health and Nutrition Examination Survey (2007-2010). J AM COLL NUTR 2017, 36(7):520-527. 